\title{
Cost-effectiveness study of early versus late parenteral nutrition in critically ill children (PEPaNIC): preplanned secondary analysis of a multicentre randomised controlled trial
}

Esther van Puffelen ${ }^{1}$, Suzanne Polinder ${ }^{2}$, Ilse Vanhorebeek ${ }^{3}$, Pieter Jozef Wouters ${ }^{3}$, Niek Bossche ${ }^{4}$, Guido Peers ${ }^{5}$, Sören Verstraete ${ }^{3}$, Koen Felix Maria Joosten ${ }^{1}$, Greet Van den Berghe ${ }^{3^{*}}$,

Sascha Cornelis Antonius Theodorus Verbruggen ${ }^{1}$ and Dieter Mesotten ${ }^{3}$

\begin{abstract}
Background: The multicentre randomised controlled PEPaNIC trial showed that withholding parenteral nutrition (PN) during the first week of critical illness in children was clinically superior to providing early PN. This study describes the cost-effectiveness of this new nutritional strategy.

Methods: Direct medical costs were calculated with use of a micro-costing approach. We compared the costs of late versus early initiation of PN ( $n=673$ versus $n=670$ patients) in the Belgian and Dutch study populations from a hospital perspective, using Student's $t$ test with bootstrapping. Main cost drivers were identified and the impact of new infections on the total costs was assessed.

Results: Mean direct medical costs for patients receiving late PN (€26.680, IQR €10.090-28.830 per patient) were 21\% lower $(€ 7.180, p=0.007)$ than for patients receiving early PN (€33.860, IQR €11.080-34.720). Since late PN was more effective and less costly, this strategy was superior to early PN. The lower costs for PN only contributed $2.1 \%$ to the total cost reduction. The main cost driver was intensive care hospitalisation costs (-€4.120,p=0.003). The patients who acquired a new infection (14\%) were responsible for $41 \%$ of the total costs. Sensitivity analyses confirmed consistency across both healthcare systems.
\end{abstract}

Conclusions: Late initiation of PN decreased the direct medical costs for hospitalisation in critically ill children, beyond the expected lower costs for withholding PN. Avoiding new infections by late initiation of PN yielded a large cost reduction. Hence, late initiation of PN was superior to early initiation of PN largely via its effect on new infections.

Trial registration: ClinicalTrials.gov, NCT01536275. Registered on 16 February 2012.

Keywords: Parenteral nutrition, Cost-effectiveness, Health economics, Costs, Intensive care

\section{Background}

Healthcare costs are growing worldwide. Intensive care is responsible for a substantial proportion of all healthcare expenses, particularly prolonged intensive care and palliative care [1-4]. Intensive care costs are largely dependent on length of stay (LOS) in the intensive care unit (ICU),

\footnotetext{
* Correspondence: greet.vandenberghe@kuleuven.be

${ }^{3}$ Clinical Division and Laboratory of Intensive Care Medicine, Department of Cellular and Molecular Medicine, University Hospitals Leuven, Leuven, Belgium

Full list of author information is available at the end of the article
}

which is strongly influenced by complications, such as hospital-acquired infections [5].

Recently, a multicentre, randomised, controlled, parallel-group, superiority trial, with the acronym PEPaNIC $(n=1.440)$ concluded that withholding parenteral nutrition (PN) during the first week of critical illness in children was clinically superior to providing PN within 24 hours when enteral nutrition was insufficient [6], resulting in fewer patients with new infections. Aside from this clinical benefit, an additional economic benefit 
of late PN would be an extra argument for implementation of this new nutritional strategy.

Currently, no studies have investigated costs of different timing of initiation of $\mathrm{PN}$ in children in the paediatric ICU (PICU). Our cost-effectiveness analysis was predesigned, offering a unique opportunity for a micro-costing approach [7]. With this method of calculating hospital costs, all relevant cost categories are included and costs are calculated at the most detailed level per patient, in contrast to the gross-costing approach, whereby the cost categories are highly aggregated or only hospitalisation costs are included.

We hypothesised that withholding PN for one week is a cost-saving strategy comprising more than merely omitting the costs of PN itself. The aims of this study were (1) to compare total direct medical costs of early versus late initiation of $\mathrm{PN}$ in the PICU from a hospital perspective in an international context, (2) to provide detailed insight into the distribution of cost components, and (3) to assess the impact of acquiring a new infection in the PICU on direct medical costs.

\section{Methods}

Context

A total of 1440 critically ill children, aged 0 (term neonates) to 17 years, from three large tertiary referral PICUs in three countries (University Hospitals Leuven in Belgium, Erasmus MC in The Netherlands, and Stollery Children's Hospital in Canada) were randomly assigned to early initiation of PN (standard care) or late initiation of PN (intervention). Initiation and dose of enteral nutrition (EN) and the administration of trace elements, minerals and vitamins were identical in both groups. Patients assigned to the group with late initiation of $\mathrm{PN}(n=717)$ received no $\mathrm{PN}$ during the first week of critical illness. Patients assigned to the group with early initiation of $\mathrm{PN}(n=723)$ received $\mathrm{PN}$ within 24 hours, according to the local standards. After the first week, when patients were still in the PICU and EN was insufficient to meet nutritional goals, PN was administered equally in both groups according to standard nutrition protocols $[6,8]$. The institutional ethical review boards of the participating centres in Leuven (ML8052), Rotterdam (NL38772.000.12) and Edmonton (Pro00038098) approved the study, which was performed in accordance with the 1964 Declaration of Helsinki and its amendments. Written informed consent was obtained from the parents or legal guardians.

In this study, we explored the total direct medical costs, from a hospital perspective, in the Belgian and Dutch study populations, as these healthcare systems are reasonably comparable. Including the patients from Canada would introduce a bias, as cost calculations and reimbursements are too differently structured in Anglo-
Saxon healthcare systems. Therefore, we excluded this centre from the cost analyses.

\section{Healthcare systems}

In the Dutch healthcare system, hospitals are mainly paid by private insurance companies according to tariffs based on "Diagnosis Therapy Combination" (DBC) [9]. However, registered DBCs per patient do not represent individualised healthcare consumption. As the tariffs are fixed, specific healthcare activities are not presented in the patients' invoices. Therefore, we used individual healthcare consumption and corresponding unit prices, which are registered by the hospital for reporting and stock management.

In Belgium, healthcare costs are reimbursed by sickness funds and private insurance companies. Since all healthcare activities are represented in the patients' invoices, these invoices can be used to accurately quantify healthcare consumption. However, total healthcare costs are mainly covered by advance payments to the hospital, directly by the government. Consequently, for healthcare activities for which the hospital receives these advance payments, only $25 \%$ of the costs are represented in the patients' invoices. When this is corrected to $100 \%$, they reflect real healthcare costs from a hospital perspective [10].

\section{Resource consumption}

The participating clinicians filled out standardised case report forms during the ICU stay, including duration of ICU dependency, post-ICU hospitalisation, mechanical ventilation, renal replacement therapy (RRT) and mechanical hemodynamic support. LOS encompassed both index and transferral hospitals. PN consumption was obtained from the study database for Dutch patients and from the invoices for Belgian patients. Detailed information on diagnostic procedures, medication, blood products, surgery and consultations were obtained from the data management system of the hospital for Dutch patients and from the invoices for Belgian patients.

Healthcare consumption was divided into ten cost categories: (1) ICU hospitalisation (both index and transferral hospital); (2) post-ICU hospitalisation (both index and transferral hospital); (3) PN; (4) medication; (5) laboratory diagnostics; (6) other diagnostics; (7) ventilator support; (8) RRT and mechanical haemodynamic support; (9) surgery; and (10) consultations from other specialists.

\section{Economic evaluation}

The cost-effectiveness analyses were based on the Dutch and Belgian guidelines for performing costs studies [10, 11]. Furthermore, this study is in line with the international Consolidated Health Economic Evaluation Reporting Standards (CHEERS) statement [12]. Real medical costs were calculated by multiplying the volumes of healthcare use with the corresponding unit prices. Costs were calculated 
during two periods. From randomisation until ready-fordischarge from ICU, or death, the costs in all aforementioned cost categories were calculated. Ready-for-discharge was a priori chosen to avoid bias due to availability of beds on regular wards and was defined as "no longer requiring or no longer at risk for requiring vital organ support". From ready-for-discharge from ICU until discharge from hospital, only hospitalisation costs were calculated. If a patient was transferred to another hospital, only hospitalisation costs were included for the period from discharge from the index hospital until discharge from the transferral hospital or death. Since the time horizon was less than one year, unit prices were not discounted.

In the Netherlands, the unit prices were available from the hospital's financial database, and were adjusted to the year 2014. For hospital days (non-ICU), a national guiding price per day was used, because children were referred to different hospitals, charging different prices [11]. The daily costs of mechanical ventilation and RRT were estimated based on published literature [13, 14]. Production costs of infusions for the intervention group were calculated by summing the costs of the PN ingredients, pharmacy compounding costs and additional trial intervention costs.

In Belgium, financial data were registered by the billing and warehousing collaborators of the index hospital as this is standard procedure for invoicing. The unit prices were official, nationally fixed prices adjusted to the year 2014 , and were converted to $100 \%$, if necessary, to obtain real costs from a hospital perspective [10]. There were no additional trial intervention costs for infusions in the group receiving late initiation of $\mathrm{PN}$.

Costs of medication were categorised according to the first level of the Anatomical Therapeutic Chemical (ATC) classification, which is the World Health Organisation (WHO) tool for drug utilisation research [15]. Each drug has its unique ATC code and price. Costs for ATC code B05BA (PN solutions) were reported separately. Since we were unable to distinguish costs per ATC code in Dutch patients, we excluded them from this ATC code analysis. However, since new infections were a primary outcome in the trial, we analysed the costs of anti-infective drugs in both centres.

\section{Study endpoints}

The primary endpoint was the difference in total direct medical costs, from a hospital perspective, between early and late initiation of PN. Furthermore, the ten cost categories were analysed separately. In order to give insight into costs among different groups of patients, we compared total direct medical costs of early initiation of PN with late initiation of $\mathrm{PN}$ in the stratification groups as used for the PEPaNIC trial: "Surgical cardiac", "Surgical other", "Medical neurological" and "Medical other", and age groups younger and older than one year [8]. Additionally, the drugs responsible for differences in medication costs were investigated based on the ATC codes. Also, the impact of new infections on total costs was calculated. Finally, we explored the cost-effectiveness of late initiation of $\mathrm{PN}$, using the number of patients with a new infection prevented in the ICU as an effect measure.

\section{Statistical analyses}

The PEPaNIC trial was a priori statistically powered to detect a difference in new infections. Therefore, the statistical power to detect differences in total direct medical costs was dependent on the number of patients enrolled in the original PEPaNIC trial. This cost analysis was an a priori planned secondary analysis.

Costs were reported in euro $(€)$, as mean (SD and IQR), as recommended for cost analyses [16]. IQR was reported, as cost data is always highly skewed, and IQR reflects the statistical dispersion more realistically than standard deviation or standard error. Other data were reported as mean (SE), median (IQR) or number (\%), as appropriate. In order to check whether the major costs were similarly distributed into the cost categories in both centres, a Pareto analysis was performed. This is a chart to demonstrate which factors are contributing most to a problem (i.e. total costs) [17].

Costs were compared univariably using Student's onetailed $t$ test with bootstrapping $(\times 1000)$ [16], LOS was compared using the Mann-Whitney $U$ test, and the incidence of new infection was compared using Fisher's exact test. Based on the clinical results that point out clearly that late PN reduces resource consumption by reduction of new infections and shorter PICU stay, we have chosen to test the differences in costs one-sided, hypothesising that late $\mathrm{PN}$ is less costly than early $\mathrm{PN}$. One-sided $p$ values $<0.05$ were considered statistically significant. Effects were reported as mean difference or odds ratio (OR) with the corresponding 95\% confidence interval (CI). The OR for acquiring a new infection was adjusted for age, risk of malnutrition (STRONGkids group), treatment centre, admission diagnosis, and degree of organ failure (PeLOD score), in line with the PEPaNIC trial [6], and also Paediatric Index of Mortality 2 (PIM2) score to adjust for risk of mortality. The adjusted OR was analysed using binary logistic regression. Analyses were conducted using IBM SPSS statistics, version 24.0.

\section{Sensitivity analyses}

Sensitivity analyses were conducted as follows:

1. The total costs were analysed using prices from the Belgian healthcare system for all patients.

2. The total costs were analysed using prices from the Dutch healthcare system for all patients. 
3. The total costs were analysed separately in the Belgian patients.

4. The total costs were analysed separately in the Dutch patients.

5. As only the hospitalisation costs of the post-ICU period were included in the primary analysis, the additional post-ICU costs (i.e. laboratory, medication costs) were left out. Since this could underestimate our results, the estimated additional post-ICU costs were added in the third sensitivity analysis. These additional post-ICU costs were estimated based on the invoices of the Belgian patients.

\section{Results}

We compared the total direct medical costs of late initiation of PN ( $\mathrm{N}=673$ patients) with those of early initiation of $\mathrm{PN}(\mathrm{N}=670$ patients) in the Dutch and Belgian study populations. The patients' baseline characteristics and main clinical outcomes are described in Table 1.

\section{Total healthcare costs and evaluation of cost drivers}

Late initiation of $\mathrm{PN}$, as compared with early initiation of $\mathrm{PN}$, reduced the mean total direct medical costs by $€ 7.180$ (95\% CI (-€12.920; $-€ 1.880), p=0.007)$ per patient (early initiation of $\mathrm{PN} € 33.860$, late initiation of $\mathrm{PN}$ $€ 26.680$ ), which is a saving of $21 \%$ (Table 2).

The major costs were divided into cost categories similarly for both centres (Additional file 1). Differences in mean costs between Belgian and Dutch patients were due to shorter duration of stay in the ICU (factor 0.55) in Belgian patients $(p<0.001)$, which might be caused by differences in patient populations. In contrast, the Belgian costs per day in ICU (mean costs of all categories summed, except hospitalisation costs post-ICU, divided by the duration of ICU stay) were higher (factor

Table 1 Baseline characteristics and main clinical outcomes

\begin{tabular}{|c|c|c|c|}
\hline & $\begin{array}{l}\text { Early PN } \\
(N=670)\end{array}$ & $\begin{array}{l}\text { Late PN } \\
(N=673)\end{array}$ & \\
\hline \multicolumn{4}{|l|}{ Baseline characteristics $^{a}$} \\
\hline Median age (IQR), years & $1.3(0.3-6.0)$ & \multicolumn{2}{|l|}{$1.4(0.2-7.0)$} \\
\hline Age < 1 year, $n(\%)$ & $311(46.4)$ & \multicolumn{2}{|l|}{$312(46.4)$} \\
\hline Male sex, $n(\%)$ & $386(57.6)$ & \multicolumn{2}{|l|}{$393(58.4)$} \\
\hline \multicolumn{4}{|l|}{ STRONGkids risk level, $n(\%)^{b}$} \\
\hline Medium & $593(88.5)$ & \multicolumn{2}{|l|}{$600(89.2)$} \\
\hline High & $77(11.5)$ & \multicolumn{2}{|l|}{$73(10.8)$} \\
\hline Median PeLOD score, first 24 hours in paediatric ICU $(I Q R)^{c}$ & $21(12-32)$ & \multicolumn{2}{|l|}{$21(11-31)$} \\
\hline Median PIM2 score $(I Q R)^{d}$ & $-2.8(-3.7 ;-1.3)$ & \multicolumn{2}{|l|}{$-2.8(-3.7 ;-1.6)$} \\
\hline Emergency admission, $n$ (\%) & $325(48.5)$ & \multicolumn{2}{|l|}{$308(45.7)$} \\
\hline \multicolumn{4}{|l|}{ Diagnostic group, $n(\%)$} \\
\hline Surgical cardiac & $264(39.4)$ & \multicolumn{2}{|l|}{$259(38.5)$} \\
\hline Surgical other & $202(30.1)$ & \multicolumn{2}{|l|}{$205(30.4)$} \\
\hline Medical neurological & $44(6.6)$ & \multicolumn{2}{|l|}{$50(7.4)$} \\
\hline Medical other & $160(23.9)$ & \multicolumn{2}{|l|}{$159(23.5)$} \\
\hline \multicolumn{4}{|l|}{ Condition on admission, $n(\%)$} \\
\hline Mechanical ventilation required & $596(90.0)$ & \multicolumn{2}{|l|}{$587(87.2)$} \\
\hline ECMO or other mechanical hemodynamic support required & $16(2.4)$ & \multicolumn{2}{|l|}{$22(3.3)$} \\
\hline Infection & $256(38.2)$ & \multicolumn{2}{|l|}{$244(36.3)$} \\
\hline \multicolumn{3}{|l|}{ Clinical primary outcomes } & $P$ value ${ }^{e}$ \\
\hline New infections, $n(\%)$ & $120(17.9)$ & $71(10.6)$ & $<0.001$ \\
\hline Median duration of stay in paediatric ICU (IQR), days ${ }^{\mathrm{e}}$ & $4(2-9)$ & $3(2-7)$ & 0.002 \\
\hline \multicolumn{4}{|c|}{ 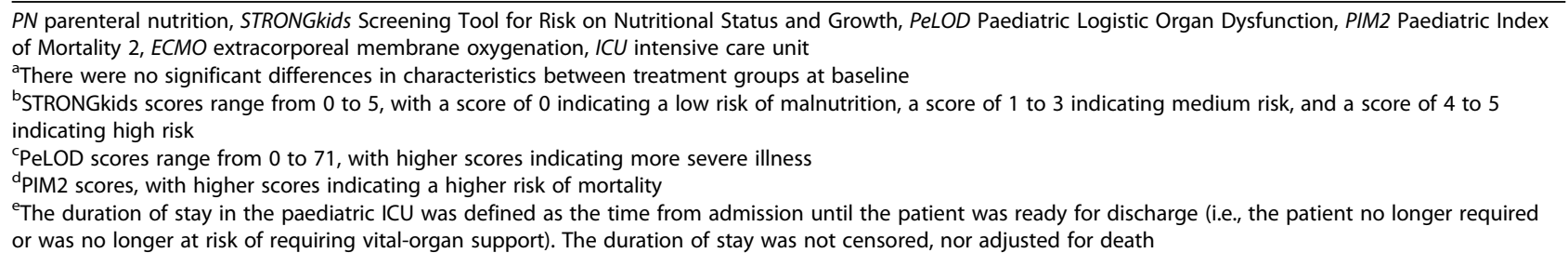 } \\
\hline
\end{tabular}


Table 2 Healthcare costs split by major cost categories

\begin{tabular}{|c|c|c|c|c|c|c|c|c|}
\hline \multirow[t]{2}{*}{ Cost category } & \multicolumn{3}{|c|}{ Early PN, € } & \multicolumn{3}{|c|}{ Late PN, $€$} & \multirow{2}{*}{$\begin{array}{l}\text { Mean difference } \\
(95 \% \mathrm{Cl}), €\end{array}$} & \multirow{2}{*}{$\begin{array}{l}P \text { value } \\
(t \text { test })\end{array}$} \\
\hline & Mean & SD & p25-p75 & Mean & SD & p25-p75 & & \\
\hline ICU hospitalisation & 13.710 & 35.130 & $2.270-13.250$ & 9.590 & 16.730 & $2.270-9.070$ & $-4.120(-7.590 ;-1.500)$ & 0.003 \\
\hline Medication & 1.810 & 7.430 & 250-1000 & 1.160 & 3.080 & $220-830$ & $-650(-1.360 ; 100)$ & 0.03 \\
\hline Ventilator support & 1.740 & 6.650 & $150-1.430$ & 1.100 & 2.300 & $150-1.070$ & $-640(-1.260 ;-190)$ & 0.03 \\
\hline Post-ICU hospitalisation & 7.140 & 14.530 & $1.500-6.900$ & 6.560 & 14.270 & $1.500-6.270$ & $-580(-2.100 ; 1.080)$ & 0.24 \\
\hline Surgery & 4.760 & 5.480 & $280-6.500$ & 4.240 & 4.260 & $200-6.280$ & $-520(-1.080 ; 10)$ & 0.03 \\
\hline Laboratory diagnostics & 2.290 & 4.090 & $540-2.160$ & 1.820 & 3.370 & $440-1.820$ & $-460(-860 ;-40)$ & 0.01 \\
\hline PN & 300 & 500 & $60-300$ & 150 & 270 & $20-170$ & $-150(-200 ;-110)$ & $<0.001$ \\
\hline Other diagnostics & 690 & 2.020 & $80-550$ & 610 & 1.610 & $80-430$ & $-80(-290 ;-110)$ & 0.20 \\
\hline Consultations & 470 & 690 & $40-680$ & 440 & 630 & $30-680$ & $-30(-100 ; 50)$ & 0.19 \\
\hline RRT and mechanical hemodynamic support & 950 & 6.740 & $0-0$ & 1.010 & 9.370 & $0-0$ & $60(-810 ; 1.020)$ & 0.45 \\
\hline Total & 33.860 & 57.610 & $11.080-34.720$ & 26.680 & 35.850 & $10.090-28.830$ & $-7.180(-12.920 ;-1.880)$ & 0.007 \\
\hline
\end{tabular}

Cost categories were ranked according to the mean difference between the treatment groups

$P N$ parenteral nutrition, $C I$ confidence interval, $I C U$ Intensive Care Unit, $R R T$ renal replacement therapy, $p 25-p 7525$ th to 75 th percentile

1.18) than the Dutch costs $(p<0.001)$. Almost all cost categories showed lower costs with late initiation of PN than with early initiation of PN. The largest reduction was in ICU hospitalisation costs $(-€ 4.120,95 \%$ CI (-€7.590; -€1.500)), medication costs (-€650, 95\% CI (-€1.360; $€ 100)$ ), and ventilator support costs (-€640, 95\% CI $(-€ 1.260$; -€190)) (Table 2). This reduction in costs is in line with the shorter ICU stay in the group receiving late initiation of PN (Table 1). PN costs were responsible for $2.1 \%(-€ 150,95 \%$ CI $(-€ 200$; $-€ 110))$ of the reduction in total costs.

The age category $(<1$ year versus $\geq 1$ year) was not apparently related to proportional cost reduction with late initiation of PN (Additional file 2). Patients admitted for a medical reason other than neurological disease had the largest cost reduction with late initiation of PN (-€14.720, 95\% CI (-€30.720; €130), $p=0.04$ ) (Additional file 3). Patients admitted for non-cardiac surgery also had cost reduction with late initiation of $\mathrm{PN}(-€ 9.490,95 \% \mathrm{CI}$ $(-€ 20.720 ; € 1.040), p=0.05)$ (Additional file 3). Furthermore, $26 \%$ of the patients had a prolonged ICU stay ( $>7$ days), accounting for $60 \%$ of the costs. Moreover, the most expensive $1 \%$ of patients accounted for $13 \%$ of the total costs.

The distribution of medication costs is described in Table 3. The combination of medications of category $B$ (blood and blood forming organs), containing PN solutions, and category J (anti-infectives), containing antibiotics, was responsible for $80 \%$ of the reduction in medication costs with late initiation of PN (Table 3).

\section{Impact of new infections}

The proportion of patients with a new infection acquired in the ICU was smaller with late initiation of PN than with early initiation of $\mathrm{PN}$ (patients included for cost analysis, $10.6 \%$ and $17.9 \%$, respectively, $p<0.001$ ) (Table 1), with a corresponding adjusted odds ratio of 0.51 (95\% CI $(0.36 ; 0.71))$. In the whole group, $1.2 \%$ of the least expensive $50 \%$ of patients had acquired a new infection compared to $28.5 \%$ of the most expensive $50 \%$ of patients. Moreover, $85 \%$ (11 patients) of the most expensive $1 \%$ of patients (13 patients) had acquired a new infection. Figure 1 depicts the cost tree of patients with and without a new infection in both randomisation groups. In patients who acquired a new infection, costs were increased from $€ 21.350$ to $€ 91.200$ (difference $€ 69.850,95 \%$ CI (€50.700; €91.560), $p=0.001$ ) with early initiation of $\mathrm{PN}$ and from $€ 20.600$ to $€ 78.210$ (difference $€ 57.610$, 95\% CI (€41.890; €73.970), $p=0.001$ ) with late initiation of PN, predominantly caused by ICU hospitalisation costs (early-PN group, difference $€ 37.210,95 \% \mathrm{CI}$ (€26.200; €52.750), $p=0.002$; late-PN group: difference $€ 27.530,95 \%$ CI (€20.660; €34.940), $p=0.001$ ).

Late initiation of PN was more effective and less costly than early initiation of $\mathrm{PN}$, and falls into the south-eastern quadrant of the cost-effectiveness plane. Interventions in this quadrant are always considered cost-effective $[18,19]$.

\section{Sensitivity analyses}

The primary results were robust, as they could be reproduced with multiple sensitivity analyses (Table 4). Using the Dutch or Belgian unit prices for all patients showed a cost difference of late versus early $\mathrm{PN}$ of $-€ 8.690$ respectively $-€ 6.090$, which is within the $95 \% \mathrm{CI}$ of the primary analysis of the base case ((-€12.920; -€1.880). Also, when analysing the Dutch and Belgian patients separately, the cost reduction with late $\mathrm{PN}$ was within the $95 \% \mathrm{CI}$ of the primary analysis of the base case (Table 4). The difference 
Table 3 Medication costs of Belgian patients split by Anatomical Therapeutic Classification (ATC) system classes

\begin{tabular}{|c|c|c|c|c|c|c|c|c|}
\hline \multirow[t]{2}{*}{ ATC code } & \multicolumn{3}{|c|}{ Early PN, € } & \multicolumn{3}{|c|}{ Late PN, € } & \multirow{2}{*}{$\begin{array}{l}\text { Mean difference } \\
(95 \% \mathrm{Cl}), €\end{array}$} & \multirow{2}{*}{$\begin{array}{l}P \text { value } \\
\text { ( } t \text { test) }\end{array}$} \\
\hline & Mean & SD & p25-p75 & Mean & SD & p25-p75 & & \\
\hline B (blood/blood forming organs) & 850 & 1.820 & $210-740$ & 580 & 1.350 & $140-480$ & $-270(-510 ;-40)$ & 0.02 \\
\hline$J\left(\right.$ anti-infectives) ${ }^{a}$ & 320 & 2500 & $4-90$ & 170 & 1.030 & $4-50$ & $-150(-470 ; 80)$ & 0.17 \\
\hline A (alimentary tract/metabolism) & 70 & 250 & $20-70$ & 50 & 80 & $10-40$ & $-30(-40 ;-10)$ & $<0.001$ \\
\hline V (various) & 100 & 140 & $20-140$ & 80 & 110 & $20-110$ & $-20(-40 ;-7)$ & 0.004 \\
\hline N (nervous system) & 90 & 180 & $30-80$ & 70 & 150 & $30-80$ & $-20(-40 ; 0)$ & 0.03 \\
\hline C (cardiovascular) & 55 & 150 & $3-50$ & 45 & 100 & $1-50$ & $-10(-30 ; 5)$ & 0.07 \\
\hline R (respiratory) & 20 & 150 & $0-0$ & 10 & 50 & $0-0$ & $-10(-30 ; 7)$ & 0.10 \\
\hline H (hormonal) & 30 & 110 & $0-30$ & 20 & 60 & $0-30$ & $-10(-20 ; 3)$ & 0.10 \\
\hline M (musculo-skeletal) & 13 & 40 & $3-10$ & 7 & 10 & $3-9$ & $-5(-10 ;-2)$ & 0.01 \\
\hline D (dermatologics) & 10 & 70 & $0-8$ & 7 & 30 & $0-8$ & $-3(-10 ; 3)$ & 0.26 \\
\hline S (sensory organs) & 3 & 5 & $0-4$ & 2 & 3 & $0-4$ & $-1(-1 ; 0)$ & 0.01 \\
\hline P (antiparasitic) & 1 & 20 & $0-0$ & 0 & 0 & $0-0$ & $1(-3 ; 0)$ & 0.19 \\
\hline G (genito-urinary/sex hormones) & 1 & 8 & $0-0$ & 1 & 8 & $0-0$ & $0(-1 ; 1)$ & 0.48 \\
\hline L (antineoplasmic/immunomodulating) & 25 & 330 & $0-0$ & 45 & 320 & $0-0$ & $20(-30 ; 60)$ & 0.26 \\
\hline Total & 1.600 & 4.663 & $380-1.260$ & 1.070 & 2.577 & $310-830$ & $-500(-1.060 ; 20)$ & 0.03 \\
\hline
\end{tabular}

Cost categories were ranked according to the mean difference between the treatment groups. $P N$ parenteral nutrition, $\mathrm{Cl}$ confidence interval, $p 25-p 7525$ th to 75th percentile

${ }^{\mathrm{a}}$ Data from both Belgian and Dutch patients

in absolute costs between the centres was predominantly due to more resource consumption in the Dutch patients (i.e. longer LOS) (Additional file 4). In the third sensitivity analysis, total post-ICU costs were estimated and added to the total ICU costs. Post-ICU costs were predominantly hospitalisation costs (85\%), which were already included in the base case. Consequently, the additional post-ICU costs of approximately $€ 1.100$ in this sensitivity analysis represented the $15 \%$ of post-ICU costs that were not included in the base case.

\section{Discussion}

This cost-effectiveness study of the PEPaNIC trial showed that the total direct medical costs were considerably lower when PN was withheld during the first week of critical illness in children as compared with early initiation of PN.

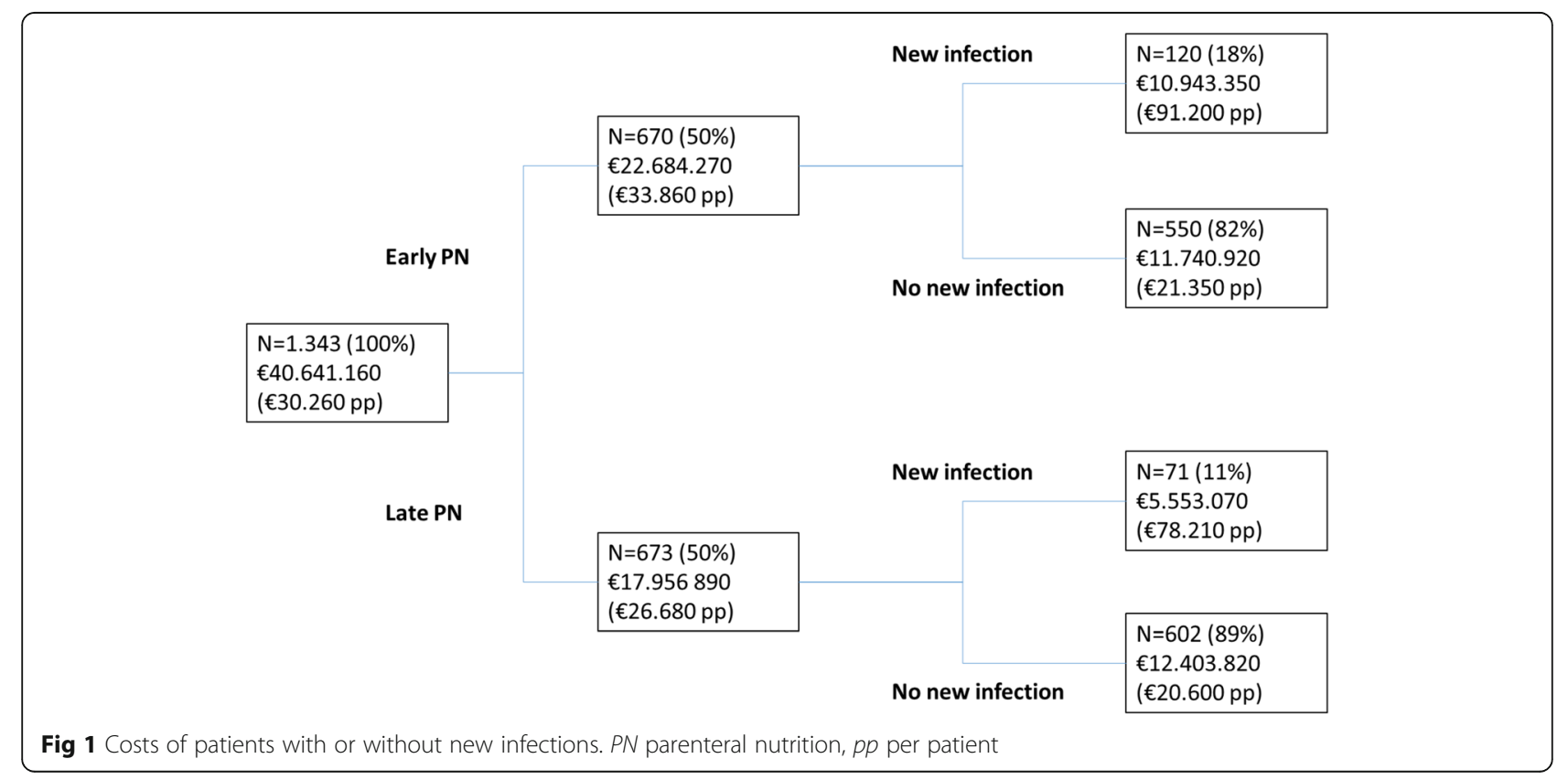


Table 4 Sensitivity analyses

\begin{tabular}{|c|c|c|c|c|c|c|c|c|c|c|}
\hline & \multicolumn{4}{|c|}{ Early PN, $€$} & \multicolumn{4}{|c|}{ Late $\mathrm{PN}, €$} & \multirow{2}{*}{$\begin{array}{l}\text { Mean difference } \\
(95 \% \mathrm{Cl}), €\end{array}$} & \multirow{2}{*}{$\begin{array}{l}P \text { value } \\
\text { ( } t \text { test })\end{array}$} \\
\hline & $N$ & Mean & SD & p25-p75 & N & Mean & SD & p25-p75 & & \\
\hline $\begin{array}{l}\text { Primary analysis (total ICU costs and } \\
\text { post-ICU hospitalisation costs) }\end{array}$ & 670 & 33.860 & 57.600 & $11.080-34.720$ & 673 & 26.680 & 35.850 & $10.090-28.830$ & $-7.180(-12.920 ;-1.880)$ & 0.007 \\
\hline \multicolumn{11}{|l|}{ Sensitivity analyses } \\
\hline 1. Belgian unit prices ${ }^{a}$ & 670 & 28.380 & 41.210 & $10.460-29.880$ & 673 & 22.290 & 24.960 & $9.320-25.390$ & $-6.090(-9.950 ;-2.480)$ & $<0.001$ \\
\hline 2. Dutch unit prices ${ }^{b}$ & 670 & 37.960 & 62.120 & $12.570-38.350$ & 673 & 29.270 & 37.180 & $11.560-32.390$ & $-8.690(-14.090 ;-3.190)$ & 0.003 \\
\hline 3. Belgian patients & 373 & 22.930 & 22.460 & $10.060-23.780$ & 377 & 17.600 & 15.920 & $9.150-19.700$ & $-5.330(-8.650 ;-2.360)$ & 0.003 \\
\hline 4. Dutch patients & 297 & 47.580 & 78.820 & $14.860-46.410$ & 296 & 38.250 & 48.630 & $12.790-42.380$ & $-9.330(-20.410 ; 1.250)$ & 0.04 \\
\hline 5. Total ICU and total post-ICU $\operatorname{costs}^{\mathrm{c}}$ & 670 & 34.990 & 58.316 & $11.470-35.580$ & 673 & 27.800 & 36.859 & $10.530-30.580$ & $-7.190(-12.420 ;-1.970)$ & 0.002 \\
\hline
\end{tabular}

$P N$ parenteral nutrition, $\mathrm{Cl}$ confidence interval, ICU Intensive Care Unit

${ }^{a}$ The total costs were analysed using prices from the Belgian healthcare system for all patients

${ }^{\text {b} T h e ~ t o t a l ~ c o s t s ~ w e r e ~ a n a l y s e d ~ u s i n g ~ p r i c e s ~ f r o m ~ t h e ~ D u t c h ~ h e a l t h c a r e ~ s y s t e m ~ f o r ~ a l l ~ p a t i e n t s ~}$

'In the primary analysis, only the hospitalisation costs of the post-ICU period were included. The estimated additional post-ICU costs (i.e. laboratory, medication)

were added. These additional post-ICU costs were estimated based on the invoices of the Belgian patients

This cost reduction was mainly due to lowering of ICU hospitalisation costs, although most cost components were reduced by not using early PN. The reduction of the costs for PN was responsible for only $2.1 \%$ of the total cutback of costs, which supported our hypothesis that the health-economic impact of withholding PN encompassed more than the omission of costs for PN itself. Taking into account the beneficial clinical impact of late initiation of $\mathrm{PN}$, we can conclude that withholding $\mathrm{PN}$ in the first week of critical illness is superior to early initiation of PN largely by preventing new infections, which is cost-saving $[18,19]$.

Our results confirmed previously published results of studies in critically ill adults that have compared early with late initiation of PN [20, 21]. The American Thoracic Society has included "withholding PN for one week in critically ill adults" in the top five recommendations to improve healthcare while reducing healthcare costs [22]. One other cost analysis of the timing of PN in adults identified no difference in LOS, and US\$ 3.170 higher costs per patient with late initiation of PN. However, the estimated costs in this study were based on a Monte Carlo simulation, in which the estimated probabilities of events, such as mechanical ventilation, have a large impact on cost differences [23]. A micro-costing approach, used in our study, provides more precise and more reliable results, as this method uses the real costs that have been incurred.

Three studies of paediatric ICU costs have been previously published, which allow comparison with our study results. First, Harron et al. reported ICU stay and direct ICU costs that are comparable to those we reported here, which supports the generalisability of the findings of our study [24]. Second, the CHiP study reported hospital costs during a 12-month period $(\sim £ 21.000)$ [4] that were slightly lower than those found in our study. These differences could be explained by different study populations, with more patients included after cardiac surgery, which may incur lower costs than medical or non-cardiac surgical paediatric ICU patients, and more patients with less organ failure, reflected by mean PeLOD of 7.5 as compared with a median PeLOD of 21 in our study. Third, Morillo-García et al. reported higher costs for children with a nosocomial infection, as compared with those without a new infection [25], which supports our conclusion that healthcare costs can be reduced by preventing new infections.

In line with previous research [26], we observed that the duration of ICU stay had a major effect on the costs. This was also reflected in the finding that patients with a prolonged ICU stay, the minority of the total patient population that was included, accounted for the majority of the costs.

The reduction in medication costs with late versus early initiation of PN was mainly due to lower use of products in ATC categories B (blood and blood-forming organs) and $J$ (anti-infectives). This corroborates the finding that late initiation of $\mathrm{PN}$ reduces the proportion of patients with new infections, as it also does in adults [21]. Additionally, patients with a new infection had higher total costs per patient than those without a new infection. The fact that the proportion of patients with new infections increased from $1.2 \%$ among the least expensive patients to $85 \%$ among the $1 \%$ most expensive patients pointed to an effect of new infections on the total costs. Therefore, reducing the number of ICU days by preventing the occurrence of new infections by late initiation of $\mathrm{PN}$ seems to have had most influence on the cost reduction.

The strength of this study is the micro-costing approach, reflecting real costs that incurred. Additionally, our findings appeared robust across two healthcare systems. We have carefully checked whether combining the 
Dutch and Belgian populations would compromise our results by performing sensitivity analyses, which have shown unanimously a cost reduction with late $\mathrm{PN}$, which was well within the range of the confidence interval of the base case. These results may support that the international character of this study increased external validity and, possibly, applicability to other European countries.

Some limitations should also be addressed. First, the Dutch daily costs of mechanical ventilation and renal replacement therapy had to be estimated, based on published literature on ICU costs $[13,14]$. Second, the time horizon was limited to the hospital period and direct medical costs, and thus, the economic consequences could not be fully captured. One Swiss study, investigating out-of-pocket expenses of families with a child spending $>4$ days in the ICU reported mean $86( \pm 31)$ Franc (converted $\sim € 137$ ) per day, mainly on travel costs and meals [27]. As such, the full impact of late initiation of PN from a societal perspective could not be assessed. Third, quality-adjusted life years (QALYs) were not used as an outcome measure, as the time horizon was too short (hospital stay) to meaningfully assess long-term quality of life of critically ill children. It is acknowledged that a cost-utility analysis is preferred over a costeffectiveness analysis, if a treatment has an impact on health-related quality of life. At this time, a long-term follow-up study is ongoing, with patients being evaluated 2 and 4 years after randomisation. This long-term follow-up study includes an assessment of quality of life. However, the aim of the current study was to perform a cost-effectiveness analysis and not a cost-utility analysis, which requires quality of life data. Finally, the lack of detailed drug costs for Dutch patients may have biased, and possibly underestimated, the differences in drug costs.

\section{Conclusion}

The cost analyses showed that late initiation of PN reduced the direct medical costs by $21 \%$ in critically ill children as compared with early initiation of PN, beyond the expected lower costs for the use of PN itself. Avoiding new infections by late initiation of PN yielded a large cost reduction. Withholding PN during the first week of critical illness in children can thus be recommended both from a clinical and a health-economic perspective.

\section{Additional files}

Additional file 1: Pareto charts of the cost categories in Belgian and Dutch patients, shown separately. (DOC $183 \mathrm{~kb}$ )

Additional file 2: Table showing total healthcare costs split by age into two groups. (DOC $28 \mathrm{~kb}$ )

Additional file 3: Table showing total healthcare costs split by diagnosis into four groups. (DOC $31 \mathrm{~kb}$ )
Additional file 4: Table showing resource utilisation and costs per centre separately in Belgian and Dutch patients respectively. (DOC 37 kb)

\section{Abbreviations}

$€$ : Euro; ATC classification: Anatomical therapeutical chemical classification; Cl: Confidence interval; DBC: Diagnosis Therapy Combination (translation from Dutch); ECMO: Extracorporeal membrane oxygenation; ICU: Intensive care unit; IQR: Interquartile range; LOS: Length of stay; OR: Odds ratio; PeLOD: Paediatric Logistic Organ Dysfunction; PIM2: Paediatric Index of Mortality 2; PN: Parenteral nutrition; RRT: Renal replacement therapy; SE: Standard error; STRONGkids: Screening Tool for Risk on Nutritional Status and Growth; US\$: American Dollar; WHO: World health organisation

\section{Acknowledgements}

Not applicable.

\section{Funding}

Supported by a grant from the Flemish Agency for Innovation through Science and Technology (IWT-TBM1 10685, to Dr. Van den Berghe), a private donation by an anonymous Dutch family through the Leuven University Hospitals to Dr. Van den Berghe, a senior clinical research fellowship from the Fund for Scientific Research Flanders to Dr. Mesotten, a grant from the Methusalem Programme funded by the Flemish Government (METH/08/07 to Dr. Van den Berghe, and METH/14/06 through KU Leuven, to Dr. Van den Berghe and Dr. Vanhorebeek), the European Research Council under the European Union's Seventh Framework Program ((FP7/2013-2018)/ERC Advanced Grant Agreement number 321670, to Dr. Van den Berghe), a grant from Fonds NutsOhra to Dr. Verbruggen, an Erasmus MC Cost-Effectiveness Research Grant to Dr. Verbruggen, and a grant from the Erasmus Trustfonds through Erasmus University Rotterdam to Dr. Verbruggen.

\section{Availability of data and materials}

The datasets used and/or analysed during the current study are available from the corresponding author on reasonable request.

\section{Authors' contributions}

EvP contributed to the financial study design, collected data, analysed and interpreted the results and was a major contributor in writing the manuscript. SP was a major contributor in the financial methodology, analysing and interpreting the results, and writing of the manuscript. IV had a major contribution to the study design and set-up, interpreting the results, and writing of the manuscript. PW contributed to the data collection and writing of the manuscript. NB provided Dutch financial data and contributed to writing the manuscript. GP provided Belgian financial data and contributed to writing the manuscript. SV contributed to data collection and writing of the manuscript. KJ had a major contribution to the study design, set-up and execution, and contributed to writing of the manuscript. GvdB initiated the study, and was a major contributor in the study design, set-up and execution, interpreting the results, and writing of the manuscript. SCV was a major contributor in the study design, set-up and execution, interpreting the results, and writing of the manuscript. DM was a major contributor in the study design, set-up and execution, analysing and interpreting the results, and writing of the manuscript. All authors read and approved the final manuscript.

\section{Ethics approval and consent to participate}

The institutional ethical review boards of the participating centres in Leuven (ML8052), Rotterdam (NL38772.000.12) and Edmonton (Pro00038098) approved the study, which was performed in accordance with the 1964 Declaration of Helsinki and its amendments. Written informed consent was obtained from the parents or legal guardians.

\section{Consent for publication}

Not applicable.

\section{Competing interests}

The authors declare that they have no competing interests.

\section{Publisher's Note}

Springer Nature remains neutral with regard to jurisdictional claims in published maps and institutional affiliations. 


\section{Author details}

'Intensive Care Unit, Department of Paediatrics and Paediatric Surgery, Erasmus Medical Centre, Sophia Children's Hospital, Rotterdam, The Netherlands. ${ }^{2}$ Department of Public Health, Erasmus Medical Centre, Rotterdam, The Netherlands. ${ }^{3}$ Clinical Division and Laboratory of Intensive Care Medicine, Department of Cellular and Molecular Medicine, University Hospitals Leuven, Leuven, Belgium. ${ }^{4}$ Department of Control and Compliance, Erasmus Medical Centre, Rotterdam, The Netherlands. ${ }^{5}$ Department Medical Administration, University Hospitals Leuven, Leuven, Belgium.

Received: 18 August 2017 Accepted: 27 December 2017 Published online: 15 January 2018

\section{References}

1. Conte T, Mitton C, Trenaman LM, Chavoshi N, Siden H. Effect of pediatric palliative care programs on health care resource utilization and costs among children with life-threatening conditions: a systematic review of comparative studies. CMAJ Open. 2015;3:E68-75.

2. Smith AG, Andrews S, Bratton SL, Sheetz J, Feudtner C, Zhong W, Maloney CG. Pediatric palliative care and inpatient hospital costs: a longitudinal cohort study. Pediatrics. 2015;135:694-700

3. Heikkila $\mathrm{P}$, Forma L, Korppi M. Hospitalisation costs for infant bronchiolitis are up to 20 times higher if intensive care is needed. Acta Paediatr. 2015;104:269-73.

4. Macrae D, Grieve R, Allen E, Sadique Z, Betts H, Morris K, Pappachan VJ, Parslow R, Tasker RC, Baines $P$, et al. A clinical and economic evaluation of control of hyperglycaemia in paediatric intensive care (CHiP): a randomised controlled trial. Health Technol Assess. 2014;18:1-210.

5. Dominguez TE, Chalom R, Costarino Jr AT. The impact of adverse patient occurrences on hospital costs in the pediatric intensive care unit. Crit Care Med. 2001;29:169-74.

6. Fivez T, Kerklaan D, Mesotten D, Verbruggen S, Wouters PJ, Vanhorebeek I, Debaveye Y, Vlasselaers D, Desmet L, Casaer MP, et al. Early versus late parenteral nutrition in critically ill children. N Engl J Med. 2016;374:1111-22. https://doi.org/10.1056/NEJMoa1514762.

7. Gold MR, Siebel JR, Russell LB, Weinstein MC. Cost-effectiveness in health and medicine. New York: Oxford University Press; 1996.

8. Fivez T, Kerklaan D, Verbruggen S, Vanhorebeek I, Verstraete S, Tibboel D, Guerra GG, Wouters PJ, Joffe A, Joosten K, et al. Impact of withholding early parenteral nutrition completing enteral nutrition in pediatric critically ill patients (PEPaNIC trial): study protocol for a randomized controlled trial. Trials. 2015;16:202. https://doi.org/10.1186/s13063-015-0728-8.

9. Nederlandse Zorgautoriteit: Prestaties en tarieven medisch specialistische zorg. In. 2016. https://www.nza.nl/regelgeving/beleidsregels/BR_CU 2147 Prestaties_en_tarieven_medisch_specialistische_zorg. Accessed 16 Nov 17.

10. Cleemput INM, Van de Sande S, Thiry N. Belgische richtlijnen voor economische evaluaties en budget impact analyses: tweede editie. Health technology assessment (HTA). Brussel: Federaal Kenniscentrum voor de Gezondheidszorg (KCE); 2012.

11. Hakkaart-van Roijen LvdL N, Bouwmans C, Kanters T, Tan SS. Kostenhandleiding: Methodologie van kostenonderzoek en referentieprijzen voor economische evaluaties in de gezondheidszorg. In. 2015. https://www.zorginstituutnederland. nl/binaries/zinl/documenten/publicatie/2016/02/29/richtlijn-voor-het-uitvoerenvan-economische-evaluaties-in-de-gezondheidszorg/Richtlijn+voor+het +uitvoeren+van+economische+evaluaties+in+de+gezondheidszorg +\%28verdiepingsmodules\%29.pdf. Accessed 16 Nov 17.

12. Husereau D, Drummond M, Petrou S, Carswell C, Moher D, Greenberg D, Augustovski F, Briggs AH, Mauskopf J, Loder E, et al. Consolidated health economic evaluation reporting standards (CHEERS) statement. Value Health. 2013;16:e1-5. https://doi.org/S1098-3015(13)00065-X.

13. Zorgautoriteit N: Prestaties en tarieven medisch specialistische zorg. In 2015. https://www.nza.nl/1048076/1048090/BR_CU_2136_Prestaties_en_ tarieven_medisch_specialistische_zorg.pdf. Accessed 16 Nov 17.

14. Tan SS, Hakkaart-van Roijen L, Al MJ, Bouwmans CA, Hoogendoorn ME, Spronk PE, Bakker J. A microcosting study of intensive care unit stay in the Netherlands. J Intensive Care Med. 2008;23:250-7. https://doi.org/ 0885066608318661.

15. ATC/DDD Index. 2016. http://www.whocc.no/atc_ddd index. Accessed 16 Nov 17.

16. Thompson SG, Barber JA. How should cost data in pragmatic randomised trials be analysed? BMJ. 2000;320:1197-200.
17. Montgomery D: Introduction to statistical quality control, 6 edn: John Wiley \& Sons, Inc; 2009. http://dl4a.org/uploads/pdf/581SPC.pdf.

18. Drummond MF, SMJ. Methods for the economic evaluation of health care programmes, 3rd edn: Oxford University Press; 2005. https://global.oup.com/ academic/product/methods-for-the-economic-evaluation-of-health-careprogrammes-9780199665877?cc=nl\&lang=en\&.

19. Fenwick E, Marshall DA, Levy AR, Nichol G. Using and interpreting costeffectiveness acceptability curves: an example using data from a trial of management strategies for atrial fibrillation. BMC Health Serv Res. 2006;6:52. https://doi.org/1472-6963-6-52.

20. Casaer MP, Mesotten D, Hermans G, Wouters PJ, Schetz M, Meyfroidt G, Van Cromphaut S, Ingels C, Meersseman P, Muller J, et al. Early versus late parenteral nutrition in critically ill adults. N Engl J Med. 2011;365:506-17. https://doi.org/:10.1056/NEJMoa1102662.

21. Vanderheyden S, Casaer MP, Kesteloot K, Simoens S, De Rijdt T, Peers G, Wouters PJ, Coenegrachts J, Grieten T, Polders K, et al. Early versus late parenteral nutrition in ICU patients: cost analysis of the EPaNIC trial. Crit Care. 2012;16:R96. https://doi.org/cc11361.

22. Halpern SD, Becker D, Curtis JR, Fowler R, Hyzy R, Kaplan LJ, Rawat N, Sessler $\mathrm{CN}$, Wunsch H, Kahn JM, et al. An official American thoracic society/ American association of critical-care nurses/American college of chest physicians/society of critical care medicine policy statement: the choosing wisely(R) Top 5 list in critical care medicine. Am J Respir Crit Care Med. 2014;190:818-26. https://doi.org/10.1164/rccm.201407-1317ST.

23. Doig GS, Simpson F, Early PN Trial Investigators Group. Early parenteral nutrition in critically ill patients with short-term relative contraindications to early enteral nutrition: a full economic analysis of a multicenter randomized controlled trial based on US costs. Clinicoecon Outcomes Res. 2013;5:36979. https://doi.org/10.2147/CEOR.S48821 ceor-5-369.

24. Harron K, Mok Q, Dwan K, Ridyard CH, Moitt T, Millar M, Ramnarayan P, Tibby SM, Muller-Pebody B, Hughes DA, et al. CATheter infections in CHildren (CATCH): a randomised controlled trial and economic evaluation comparing impregnated and standard central venous catheters in children. Health Technol Assess. 2016;20:vii-xxviii. https://doi.org/10.3310/hta20180.

25. Morillo-Garcia A, Aldana-Espinal JM, Olry De Labry-Lima A, Valencia-Martin R, Lopez-Marquez R, Loscertales-Abril M, Conde-Herrera M. Hospital costs associated with nosocomial infections in a pediatric intensive care unit. Gac Sanit. 2015;29:282-7

26. Smeets IA, Tan EY, Vossen HG, Leroy PL, Lousberg RH, van Os J, Schieveld JN. Prolonged stay at the paediatric intensive care unit associated with paediatric delirium. Eur Child Adolesc Psychiatry. 2010;19:389-93. https://doi. org/10.1007/s00787-009-0063-2

27. Wasserfallen JB, Bossuat $C_{1}$, Perrin $E_{t}$ Cotting J. Costs borne by families of children hospitalized in a pediatric intensive care unit: a pilot study. Swiss Med Wkly. 2006:136:800-4. https://doi.org/smw-11585.

\section{Submit your next manuscript to BioMed Central and we will help you at every step:}

- We accept pre-submission inquiries

- Our selector tool helps you to find the most relevant journal

- We provide round the clock customer support

- Convenient online submission

- Thorough peer review

- Inclusion in PubMed and all major indexing services

- Maximum visibility for your research

Submit your manuscript at www.biomedcentral.com/submit
Biomed Central 